Article

\title{
Significantly Improved Catalytic Performance of Ni-Based MgO Catalyst in Steam Reforming of Phenol by Inducing Mesostructure
}

\author{
Xiaoxuan Yang, Yajing Wang and Yuhe Wang * \\ College of Chemistry and Chemical Engineering, Harbin Normal University, Harbin 150025, \\ China; E-Mails: hola.yangxiaoxuan@foxmail.com (X.Y.); wangyajinghsd@126.com (Y.W.) \\ * Author to whom correspondence should be addressed; E-Mail: wangyuhe@hrbnu.edu.cn; \\ Tel.: +86-451-8806-0570; Fax: +86-451-8632-9715.
}

Academic Editor: Keith Hohn

Received: 6 September 2015 / Accepted: 13 October 2015 / Published: 16 October 2015

\begin{abstract}
A Ni/meso-MgO catalyst with high surface area and small Ni nanoparticles was synthesized and investigated for hydrogen production by steam reforming of phenol for the first time. Compared to conventional $\mathrm{Ni} / \mathrm{MgO}$, the $\mathrm{Ni} / \mathrm{meso}-\mathrm{MgO}$ catalyst showed higher catalytic activity and stability. X-ray Diffraction, $\mathrm{N}_{2}$ adsorption, hydrogen temperature programmed reduction, transmission electron microscopy and thermal gravimetry results indicated that the $\mathrm{Ni} /$ meso-MgO catalyst had higher surface area than $\mathrm{Ni} / \mathrm{MgO}$ and $\mathrm{Ni}$ particles of $\mathrm{Ni} /$ meso-MgO were narrowly distributed in the range of $5 \sim 6 \mathrm{~nm}$ with an average size of $5.3 \mathrm{~nm}$, while Ni particles of $\mathrm{Ni} / \mathrm{MgO}$ were in the range of $6 \sim 10 \mathrm{~nm}$ with an average size of $7.92 \mathrm{~nm}$. The small and uniform Ni nanoparticles in Ni/meso-MgO were attributed to the high surface area and the confinement effect of the mesoporous structure of meso-MgO, which could effectively limit the growth of the active metal and stabilize Ni particles during the procedure of $\mathrm{NiO}$ reduction. The mesoporous structure of $\mathrm{Ni} /$ meso-MgO also played an important role in suppressing $\mathrm{Ni}$ nanoparticle sintering and carbon deposition during the steam reforming of phenol reaction.
\end{abstract}

Keywords: mesoporous $\mathrm{MgO}$; $\mathrm{Ni} / \mathrm{MgO}$ catalyst; confinement effect; steam reforming of phenol; hydrogen production 


\section{Introduction}

Hydrogen produced from renewable resources, e.g., biomass, without net contribution to $\mathrm{CO}_{2}$ emissions, is one of the most promising clean fuels [1]. Biomass gasification for hydrogen production is a fast developing technology [2]. However, one critical challenge for biomass gasification application is avoiding the formation of tar or eliminating tar [3]. Tars, products usually formed during biomass gasification, are aromatic hydrocarbons containing about $5.0 \mathrm{wt}$ \% phenolic compounds [4]. Eliminating tar by catalytic steam reforming of the gasification products is an attractive approach because steam reforming can convert tar components into $\mathrm{H}_{2}$ and other useful chemicals [5]. Ni-based catalysts are the extensively studied catalysts for steam reforming of organic hydrocarbons due to their low cost and initial high catalytic activity [6,7]. Unfortunately, thermal sintering and coke deposition are the major drawbacks of Ni-based catalysts which cause catalyst deactivation [8]. Efforts have been made for Ni-based catalysts with resistance to Ni sintering and coke deposition by reducing the particle size of active metal, forming inactive carbon [9,10], and employing strong Lewis bases as catalyst supports [11]. Although some encouraging results have been obtained, developing Ni-based catalysts with both high catalytic activity and stability for steam reforming of organic hydrocarbons still remains a challenge.

To develop a Ni-based catalyst with high resistance to $\mathrm{Ni}$ sintering and coke deposition during steam reforming, three factors are extremely important. The first one is small nickel particles, which are known to inhibit the nucleation of coke [12]; The second one is use of strong Lewis bases as catalyst supports [11], which can reduce/suppress carbon deposition and increase the rate of coke gasification by enhancing the adsorption of water [13]; The last one is a confined space that could limit $\mathrm{Ni}$ sintering. Considering these three factors, we propose a nickel-based catalyst supported on mesoporous $\mathrm{MgO}$ could be a promising catalyst. $\mathrm{MgO}$ was used because $\mathrm{NiO}$ and $\mathrm{MgO}$ can form theoretically ideal solid solution in any molar ratio and the strong interaction between them is helpful for preventing Ni particle sintering and the coke deposition [14,15]. Mesoporous MgO instead of commercial MgO was used because the higher specific surface area induced by mesopores favored the dispersion of $\mathrm{Ni}$ metal particles and the "confinement effect" of mesopores limited the growth of $\mathrm{Ni}$ particles during catalyst preparation and subsequent reaction [16,17]. In addition, mesopores improved the mass transfer of the reactants and products.

Herein, we synthesized $\mathrm{Ni} / \mathrm{meso}-\mathrm{MgO}$ catalyst and investigated its performance for steam reforming of phenol for hydrogen production for the first time. A conventional $\mathrm{Ni} / \mathrm{MgO}$ catalyst was also synthesized and compared with $\mathrm{Ni} /$ meso-MgO.

\section{Results and Discussion}

\subsection{Catalyst Characterization}

\subsubsection{XRD Studies}

Figure 1 shows the small-angle XRD patterns of meso-MgO support, fresh $\mathrm{NiO} / \mathrm{meso}-\mathrm{MgO}$ solid solution, reduced $\mathrm{Ni} /$ meso-MgO catalyst and used $\mathrm{Ni} /$ meso-MgO catalyst. Clearly, all the four samples exhibit an obvious diffraction peak at around $0.82^{\circ}$, indicating the presence of mesostructure in these 
samples. Note that the XRD diffraction peak intensity of the fresh $\mathrm{NiO} / \mathrm{meso}-\mathrm{MgO}$ solid solution is lower than that of meso-MgO, which was caused by the decline of the order of mesoporous structure when $\mathrm{NiO}$ loaded on the pore wall of meso-MgO. The similar decrease in the diffraction peak intensity was also observed over the used $\mathrm{Ni} / \mathrm{meso}-\mathrm{MgO}$ catalyst compared to the fresh one, suggesting that mesoporous structure partially degraded.

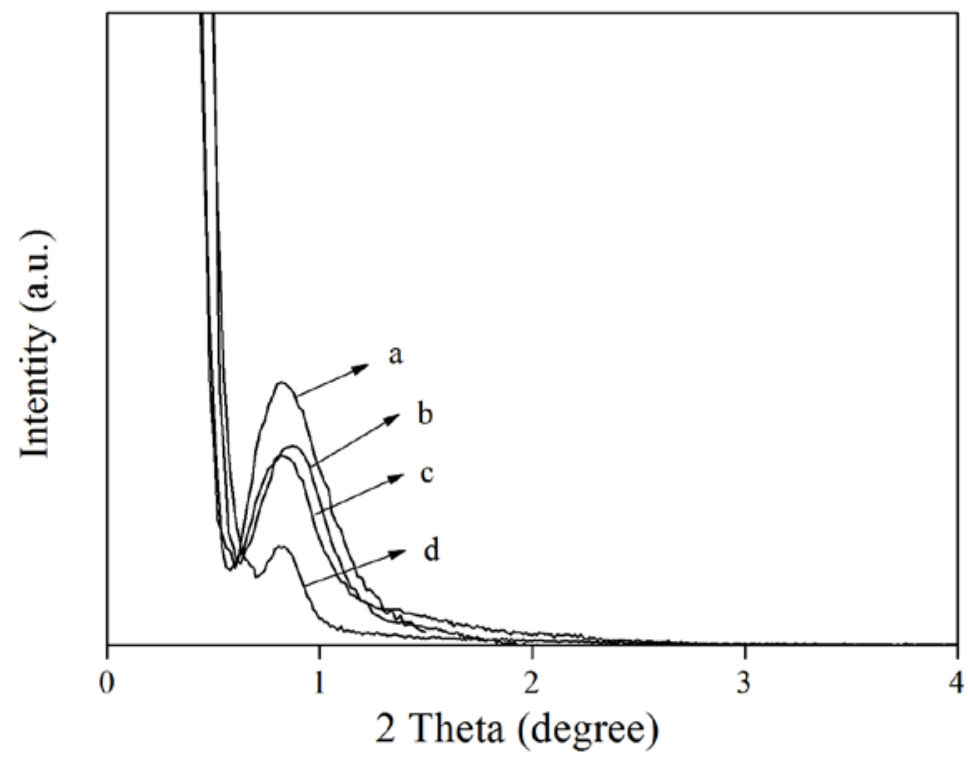

Figure 1. XRD patterns at low angle for (a) meso-MgO; (b) NiO/meso-MgO solid solution; (c) reduced Ni/meso-MgO catalyst; (d) used Ni/meso-MgO catalyst.

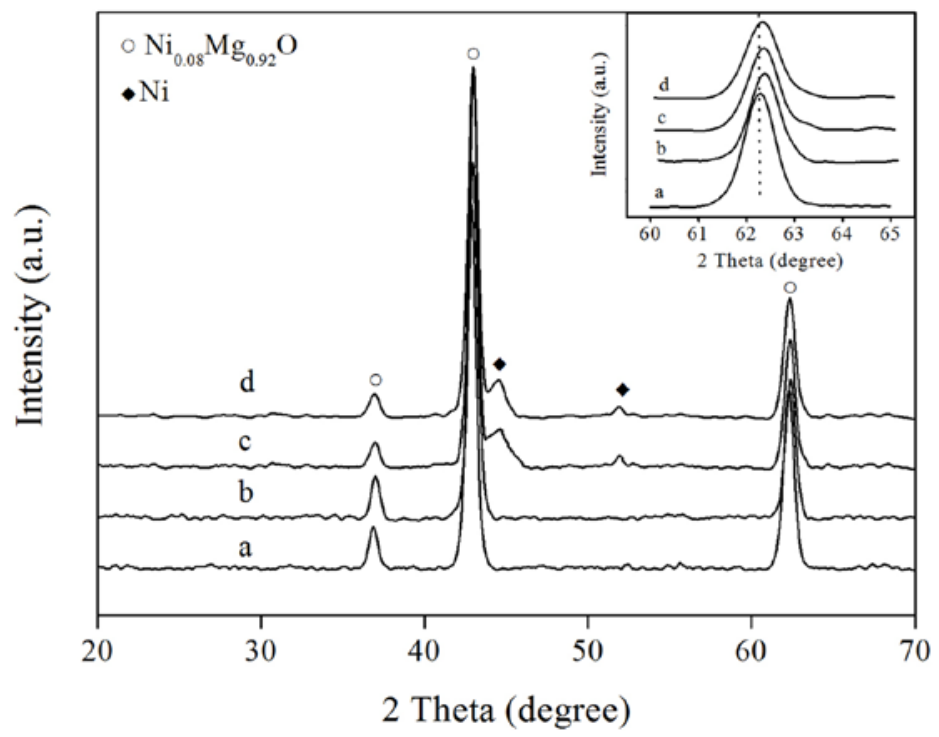

Figure 2. XRD patterns at wide angle for (a) meso-MgO; (b) $\mathrm{NiO} / \mathrm{meso}-\mathrm{MgO}$ solid solution; (c) reduced $\mathrm{Ni} /$ meso-MgO catalyst; (d) used Ni/meso-MgO catalyst after reaction for $6 \mathrm{~h}$.

Figures 2 and 3 compare the wide-angle XRD patterns of $\mathrm{Ni} / \mathrm{meso}-\mathrm{MgO}$, and its counterpart without a mesoporous structure, $\mathrm{Ni} / \mathrm{MgO}$, respectively. The peaks at $36.6^{\circ}, 42.6^{\circ}, 62.3^{\circ}$ are attributed to the (111), (200) and (220) facets of MgO, respectively (JCPDS PDF date No.45-946). The diffraction peaks at $44.5^{\circ}$ and $51.8^{\circ}$ of the reduced $\mathrm{Ni} /$ meso-MgO and the reduced $\mathrm{Ni} / \mathrm{MgO}$ shown in 
Figures 2c and 3c are assigned to the crystalline planes (111) and (200) of Ni. Compared with the supports, it can be seen that $\mathrm{NiO} / \mathrm{MgO}$ peak positions slightly shifted to higher angles after nickel loading, and no apparent $\mathrm{NiO}$ diffraction peak was observed for all the samples, indicating that the solid solution was formed via incorporation of $\mathrm{NiO}$ into MgO bulk during calcination [18].

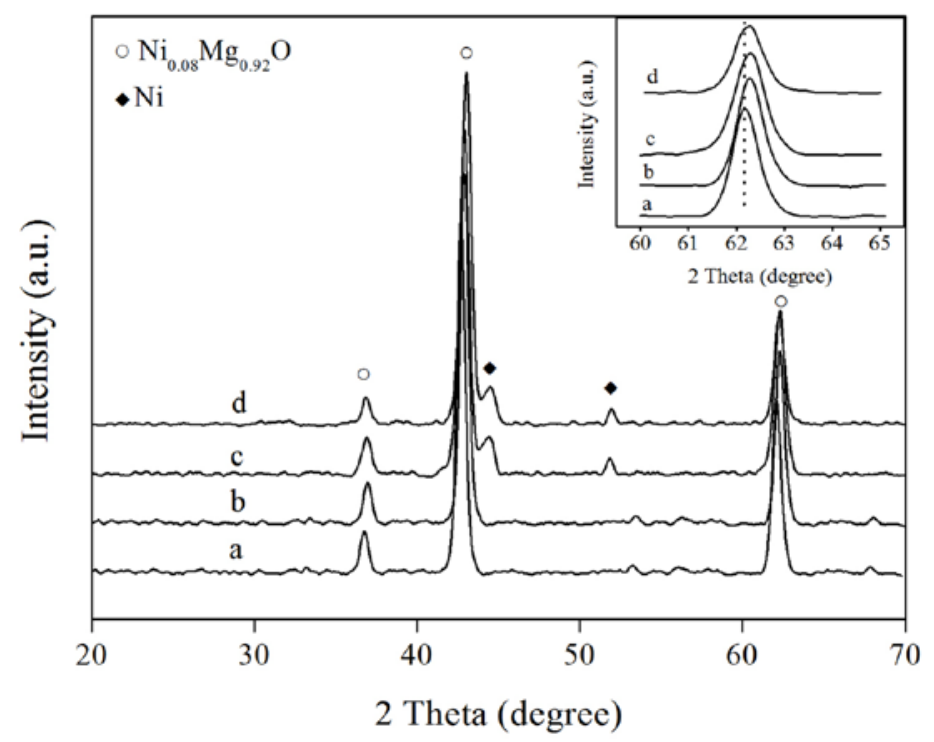

Figure 3. XRD patterns at wide angles for (a) $\mathrm{MgO}$; (b) $\mathrm{NiO} / \mathrm{MgO}$ solid solution; (c) reduced $\mathrm{Ni} / \mathrm{MgO}$ catalyst; (d) used $\mathrm{Ni} / \mathrm{MgO}$ catalyst after reaction for $6 \mathrm{~h}$.

\subsection{2. $\mathrm{N}_{2}$ Adsorption}

$\mathrm{N}_{2}$ adsorption isotherms as well as pore size distributions are exhibited in Figures 4 and 5, respectively. The textural parameters are summarized in Table 1. It is worth noting that the specific surface area of mesoporous $\mathrm{MgO}$ is 2.3 times that of conventional MgO (see Table 1). In addition, the BET surface area of $\mathrm{NiO} /$ meso-MgO is about 2.1 times that of $\mathrm{NiO} / \mathrm{MgO}$. As seen in Figure 4, mesoporous $\mathrm{MgO}$ and $\mathrm{NiO} /$ meso-MgO exhibit the type IV isotherms according to the IUPAC classification with hysteresis loops between H3 (Figure 4b) and H1 (Figure 4d) [19,20]. The results confirm the presence of mesoporous structure in these samples, in agreement with XRD results [21]. In comparison, the $\mathrm{N}_{2}$ adsorption isotherms of conventional $\mathrm{MgO}$ and $\mathrm{NiO} / \mathrm{MgO}$ did not show any hysteresis loops (see Figure 4a,c). In addition, the pore size distributions of mesoporous $\mathrm{MgO}$ and $\mathrm{NiO}$ /meso-MgO are exhibited in Table 1 and Figure 5. The pore size distributions are in the range of $8.0 \sim 9.0 \mathrm{~nm}$. Note that incorporation of $\mathrm{Ni}$ into meso-MgO reduced the specific surface area and pore volume of meso-MgO (see Table 1). This is due to the partial pore-blocking upon impregnation of $\mathrm{Ni}$ [22]. It is interesting to note that the pore size of $\mathrm{NiO} / \mathrm{meso}-\mathrm{MgO}$ is larger than that of mesoporous MgO support (Figure 5 and Table 1), which suggests that adjacent mesopores merged into larger mesopores during the preparation of $\mathrm{NiO} /$ meso-MgO [23]. 


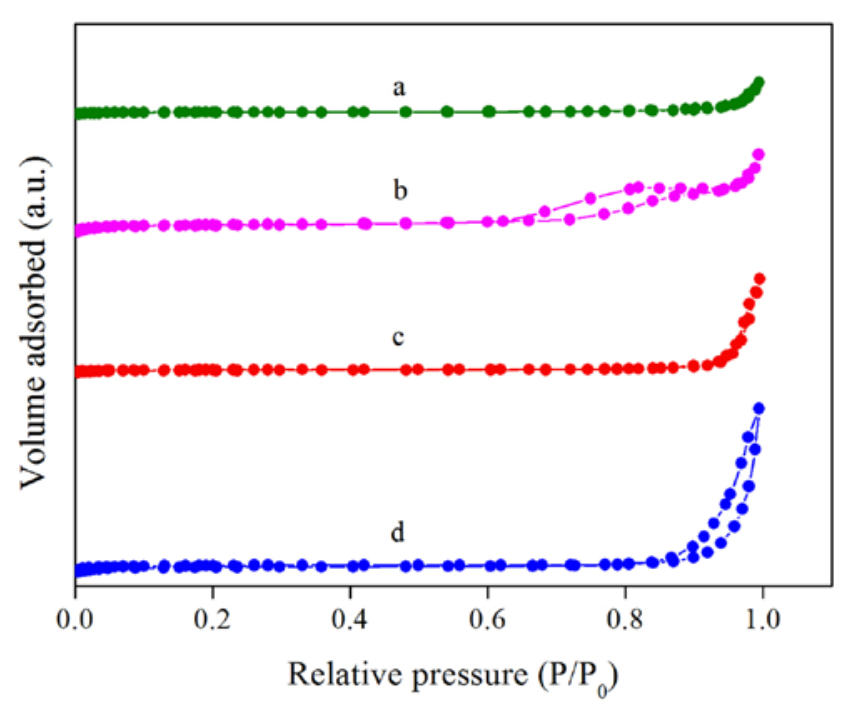

Figure 4. $\mathrm{N}_{2}$ adsorption-desorption isotherm plots for (a) $\mathrm{MgO}$; (b) meso-MgO; (c) $\mathrm{NiO} / \mathrm{MgO}$ solid solution; (d) $\mathrm{NiO} /$ meso-MgO solid solution.

\subsubsection{TEM Analysis of MgO Supports and Reduced Ni-Based Catalysts}

TEM was further employed to study the structure of MgO (Figure 6a) and meso-MgO (Figure 6b). As shown in Figure 6b, worm-like mesopores and channels can be clearly observed on the surface of meso-MgO. This is in good agreement with the results of small-angle XRD and $\mathrm{N}_{2}$ adsorption isotherms (see Figures 1 and 5). The mesopores are randomly arranged but their size is uniform. While there are no mesopores but only irregular particles observed for MgO sample (Figure 6a). HRTEM images (inset) further confirm the MgO nature of both samples. The lattice fringes for both samples have distances of $d=0.243 \mathrm{~nm}$, the (111)-spacing of the MgO structure, $d=0.211 \mathrm{~nm}$, corresponding to the (200)-spacing, or $d=0.149 \mathrm{~nm}$, which belongs to the (220)-spacing.

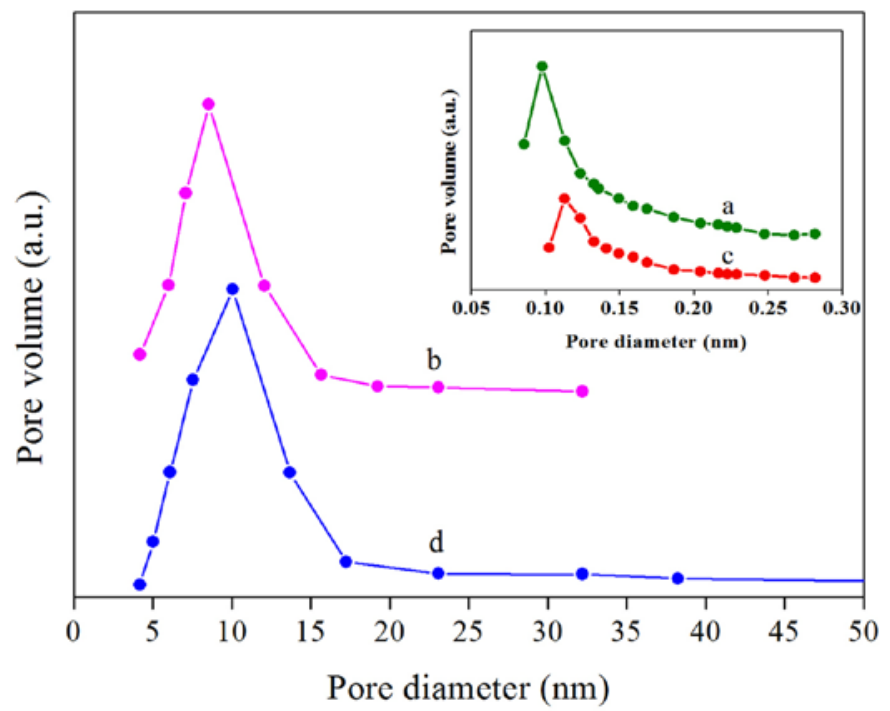

Figure 5. HK cumulative pore distribution (inset) for (a) $\mathrm{MgO}$; (c) $\mathrm{NiO} / \mathrm{MgO}$ solid solution and $\mathrm{BJH}$ cumulative pore distribution for (b) meso-MgO; (d) $\mathrm{NiO} /$ meso-MgO solid solution. 
Table 1. Physical properties of MgO supports and catalyst precursors.

\begin{tabular}{cccc}
\hline Samples & BET Surface Area $\left(\mathbf{m}^{2} / \mathbf{g}\right)$ & Pore Size $\mathbf{( n m})$ & Pore Volume $\left(\mathbf{c m}^{\mathbf{3}} \mathbf{g}\right)$ \\
\hline $\mathrm{MgO}$ & 28.60 & $0.13^{\mathrm{a}}$ & 0.05 \\
$\mathrm{meso}-\mathrm{MgO}$ & 66.36 & $8.54^{\mathrm{b}}$ & 0.30 \\
$\mathrm{NiO} / \mathrm{MgO}$ & 29.14 & $0.11^{\mathrm{a}}$ & 0.13 \\
$\mathrm{NiO} / \mathrm{meso}-\mathrm{MgO}$ & 60.59 & $10.06^{\mathrm{b}}$ & 0.26 \\
\hline
\end{tabular}

a The data from HK cumulative pore distribution; ${ }^{\mathrm{b}}$ The data from BJH cumulative pore distribution.
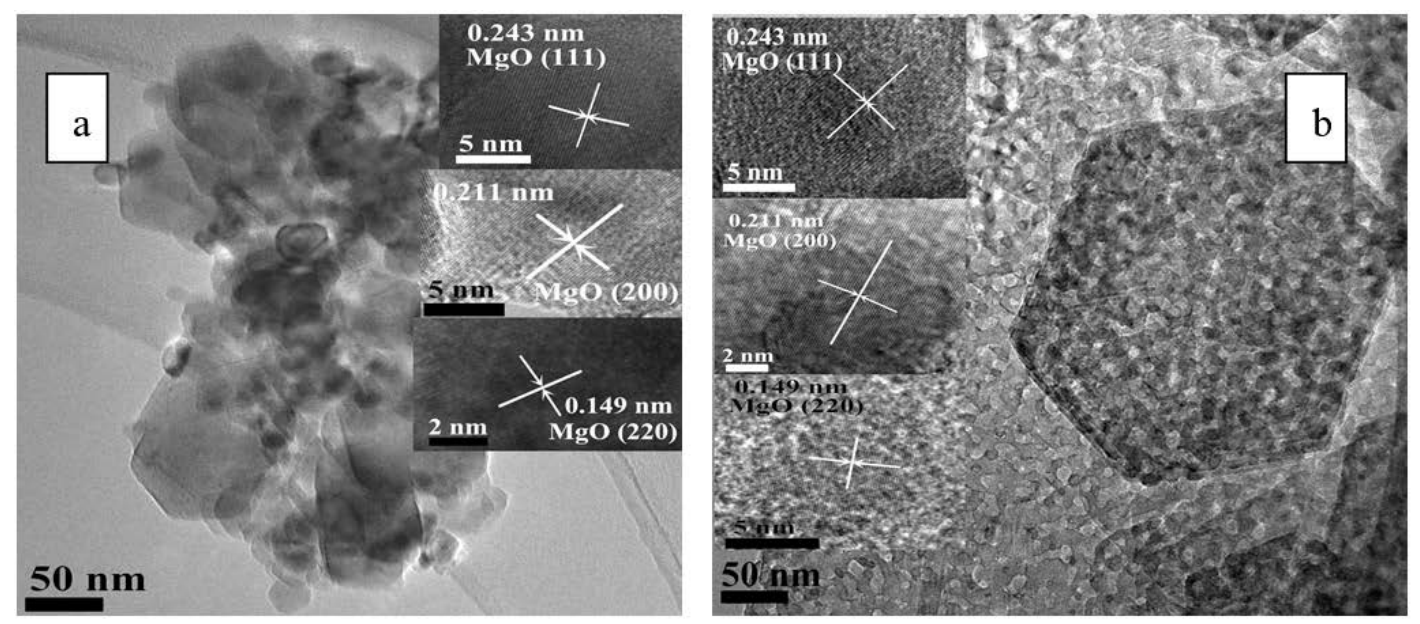

Figure 6. TEM images for (a) $\mathrm{MgO}$ and (b) meso-MgO.
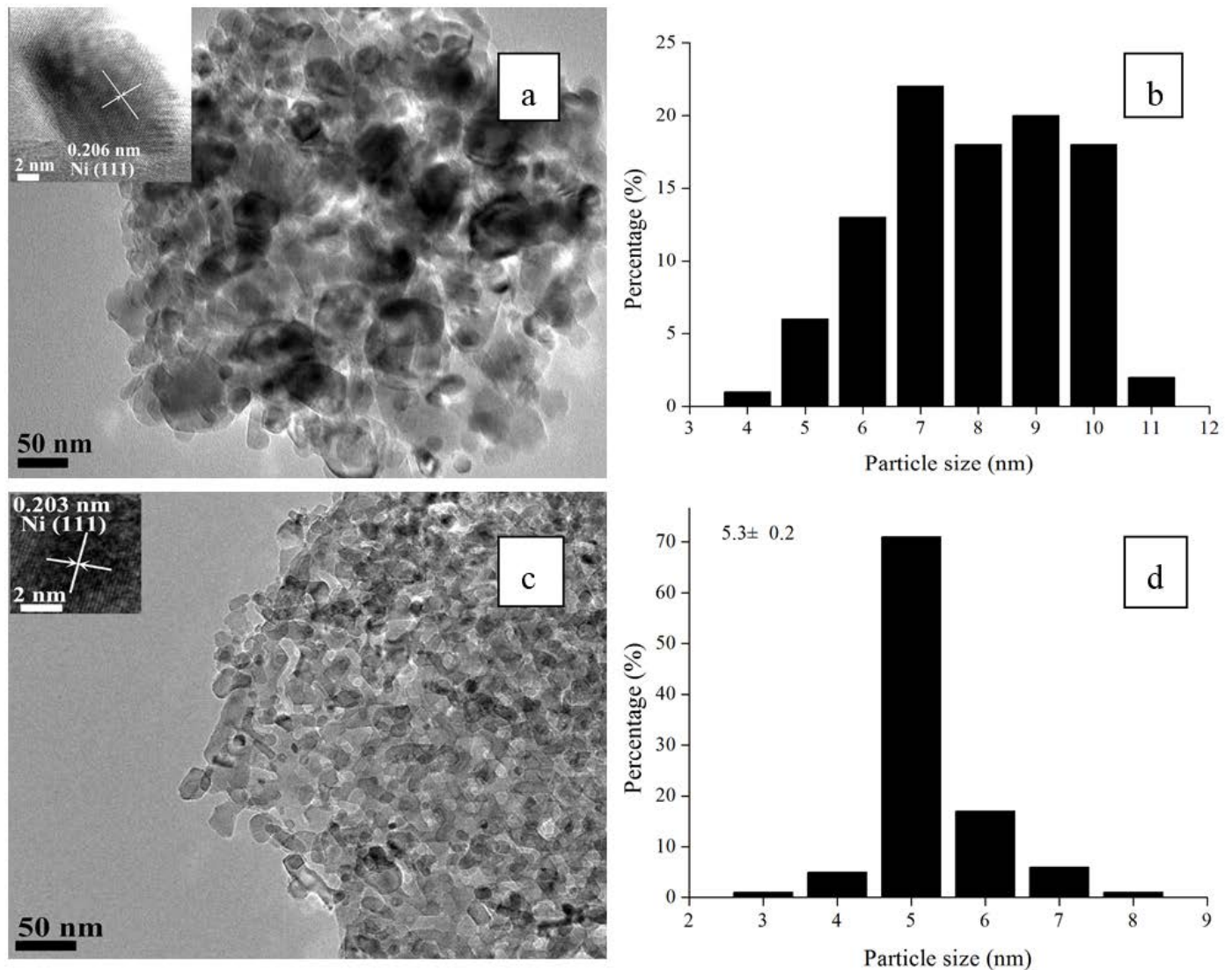

Figure 7. TEM images and Ni size distribution patterns for (a,b) reduced Ni/MgO catalyst and $(\mathbf{c}, \mathbf{d})$ reduced $\mathrm{Ni} /$ meso-MgO catalyst. 
The structures of the reduced $\mathrm{Ni} / \mathrm{MgO}$ and $\mathrm{Ni} /$ meso-MgO catalysts are shown in Figure 7. As shown in Figure 7b,d, the black spots are Ni particles distributed on the external surface of the reduced sample. HRTEM images in Figure 7a (inset) and Figure 7c (inset) show clearly lattice fringes of $0.2045 \pm 0.0015 \mathrm{~nm}$ matching that of the (111) crystallographic plane of Ni. For Ni/MgO sample from Figure 7a, Ni particles (dark spots) are randomly distributed on the whole support. In addition, the size of nickel particle on $\mathrm{Ni} / \mathrm{MgO}$ is in the range of $5 \mathrm{~nm}$ to $10 \mathrm{~nm}$ and the average size is $7.92 \mathrm{~nm}$ based on more than 100 particles (see Figure $7 \mathrm{~b}$ ). While for $\mathrm{Ni} / \mathrm{meso}-\mathrm{MgO}$, the average $\mathrm{Ni}$ particle size is $5.30 \mathrm{~nm}$ (Figure 7d), which is a good agreement with the XRD analysis (see Table 2). Figure 7c also shows that the mesoporous channels $(10.06 \mathrm{~nm})$ were well maintained after metallic Ni loading. Considering that the $\mathrm{Ni}$ particle was uniform and well distributed and the size of Ni particle is $5.30 \mathrm{~nm}$ compared to mesopores $(8.54 \mathrm{~nm})$ of mesoporous $\mathrm{MgO}$ support, mesoporous MgO support played a confinement role in the distribution and growth of $\mathrm{Ni}$ particle during the preparation of Ni/meso-MgO.

Table 2. Physical and chemical properties of Ni-based MgO catalysts.

\begin{tabular}{|c|c|c|c|c|c|c|c|}
\hline \multirow{2}{*}{ Samples } & \multirow{2}{*}{$\begin{array}{l}\text { Ni Loading } \\
\text { (wt. \%) }\end{array}$} & \multirow{2}{*}{$\begin{array}{c}\text { Ni Reducibility a } \\
(\%)\end{array}$} & \multicolumn{2}{|c|}{ Ni Size (nm) } & \multirow{2}{*}{$\begin{array}{c}\text { Ni Dispersion a } \\
(\%)\end{array}$} & \multirow{2}{*}{ 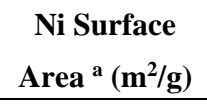 } & \multirow{2}{*}{$\operatorname{TOF}^{d}\left(s^{-1}\right)$} \\
\hline & & & By TEM $^{\mathrm{b}}$ & By XRD c & & & \\
\hline $\mathrm{Ni} / \mathrm{MgO}$ & 10.98 & 14.57 & 7.92 & 7.73 & 14.21 & 13.88 & 6.43 \\
\hline $\mathrm{Ni} / \mathrm{meso}-\mathrm{MgO}$ & 10.98 & 12.29 & 5.30 & 5.17 & 19.44 & 16.02 & 6.48 \\
\hline
\end{tabular}

${ }^{\text {a }} \mathrm{Ni}$ reducibility, $\mathrm{Ni}$ dispersion, $\mathrm{Ni}$ surface area were all calculated from the XRD results; ${ }^{\mathrm{b}} \mathrm{Ni}$ particle size was calculated using weighted average from the TEM results; ${ }^{\mathrm{c}}$ Average Ni particle size was calculated using Scherrer Formula from the XRD results;

${ }^{d}$ Turnover frequency (TOF) was calculated from the moles of phenol conversion in $1 \mathrm{~s}$ over per mole of metallic Ni contained in the catalyst; $\operatorname{TOF}\left(\mathrm{s}^{-1}\right)=$ feed flow rate $\times X_{\text {phenol }} / M_{\text {phenoo }} / 3600 / n_{\text {exposed Ni }}$ after $1 \mathrm{~h}$ of reaction.

\subsubsection{TPR Test of Catalyst Precursors}

The $\mathrm{H}_{2}$-TPR tests were conducted to simulate the reduction procedure of Ni-based MgO catalysts in situ, which the temperature was held at $650{ }^{\circ} \mathrm{C}$ for $1.0 \mathrm{~h}$ to determine the corresponding reduction degree of $\mathrm{Ni}$, and discriminate various species in solid solutions at this temperature programmed process. The TPR profile is illustrated in Figure 8 and the physical and chemical properties of Ni-based MgO catalysts are shown in Table 2.

The curves in Figure 8 disclose two apparent reduction peaks at around 375 and $565{ }^{\circ} \mathrm{C}$, respectively. The former associated with reduction of $\mathrm{Ni}^{2+}$ ions located at the surface layer of the solid solution, the latter with a small shoulder peak could be attributed to sublayer $\mathrm{Ni}^{2+}$ reduction [24]. For the two catalysts, the first peak of $\mathrm{Ni} /$ meso-MgO appeared at higher temperature. In addition, the intensity of the reduction peak decreased as the particle size of $\mathrm{Ni}$ in catalysts decreased, demonstrating that small $\mathrm{Ni}$ particles were reduction resistant [25]. This also implies that small $\mathrm{Ni}$ particles with high surface area (the surface areas of $\mathrm{Ni} / \mathrm{MgO}$ and $\mathrm{Ni} / \mathrm{meso}-\mathrm{MgO}$ catalysts are 13.88 and $16.02 \mathrm{~m}^{2} / \mathrm{g}$ in Table 2, respectively.) have reasonably strong interaction with the surfaces of meso-MgO support thus suppressing the reduction of the particles that are limited to mesoporous material. In contrast, the big particles have less contact area with the support, consequently resulting in more reduction of $\mathrm{NiO}$ to $\mathrm{Ni}[26,27]$. The calculated reduction degrees of $\mathrm{Ni}$ species are listed in Table 2. Only $14.57 \%$ and $12.29 \%$ of $\mathrm{Ni}$ species in the fresh $\mathrm{NiO} / \mathrm{MgO}$ and $\mathrm{NiO} / \mathrm{meso}-\mathrm{MgO}$ solid 
solutions were reduced to metallic $\mathrm{Ni}$. It indicates that a less amount of $\mathrm{Ni}$ was reduced on the mesoporous catalyst than that on the conventional catalyst.

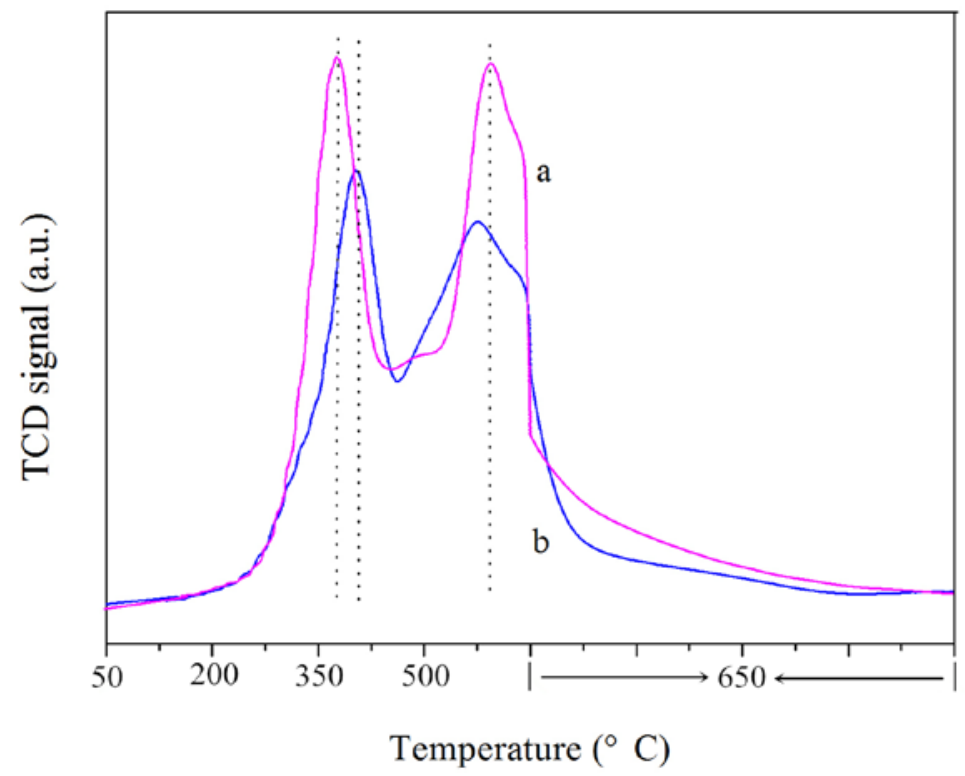

Figure 8. TPR for (a) $\mathrm{NiO} / \mathrm{MgO}$ catalyst and (b) NiO/meso-MgO catalyst.

\subsection{Catalytic Properties}

\subsubsection{Catalytic Activity}

$\mathrm{H}_{2}$ production by steam reforming of phenol was carried out over these catalysts, and the reaction conditions were $0.3 \mathrm{~g}$ catalyst at $450{ }^{\circ} \mathrm{C}, \mathrm{N}_{2}$ flow rate $=45 \mathrm{~mL} / \mathrm{min}$, liquid follow rate $=5.2 \mathrm{~mL} / \mathrm{h}$, $\mathrm{S} / \mathrm{C}=20 \mathrm{~mol} / \mathrm{mol}$. As shown in Figure 9, Ni/MgO exhibited lower activity and rapid deactivation during the 6 h of reaction. In addition, the conversion of phenol decreased from $81.5 \%$ to $62.9 \%$. In contrast, $\mathrm{Ni} /$ meso-MgO exhibited relatively higher activity and stability under the same reaction conditions. The phenol conversion over $\mathrm{Ni} /$ meso-MgO was still up to $83.1 \%$ even after reaction for $6 \mathrm{~h}$. In addition, the yield of $\mathrm{H}_{2}$ over $\mathrm{Ni} / \mathrm{MgO}$ was as low as $37.4 \%$. However, the yield of $\mathrm{H}_{2}$ over $\mathrm{Ni} /$ meso-MgO kept at $49.9 \%$ after reaction for $6 \mathrm{~h}$. Meanwhile, the $\mathrm{H}_{2}$ selectivities over $\mathrm{Ni} / \mathrm{MgO}$ and $\mathrm{Ni} / \mathrm{meso}-\mathrm{MgO}$ catalysts were $65.9 \%$ and $85.2 \%$, respectively. Based on the results shown in Figure 9, it can be concluded that the activity and stability of $\mathrm{Ni} /$ meso-MgO catalyst are much higher than those of $\mathrm{Ni} / \mathrm{MgO}$ catalyst. The gaseous products distribution was added and listed in Table 3. It was found that $\mathrm{H}_{2}$ was the main gas product, whereas $\mathrm{CO}$ and $\mathrm{CO}_{2}$ were present in small amounts. Throughout the whole experiment, $\mathrm{CH}_{4}$ was not observed.

Table 3. The conversions of Phenol, $\mathrm{H}_{2}$ yield and selectivities to the product over various catalysts.

\begin{tabular}{ccccccc}
\hline \multirow{2}{*}{ Catalyst } & \multirow{2}{*}{$\boldsymbol{X}_{\text {Phenol }}(\mathbf{*} \%)$} & \multirow{2}{*}{$\mathbf{H}_{\mathbf{2}}$ Yield (\%) } & \multicolumn{5}{c}{ Selectivity (\%) } \\
\cline { 4 - 7 } & & & $\mathbf{H}_{\mathbf{2}}$ & $\mathbf{C O}$ & $\mathbf{C O}_{\mathbf{2}}$ & $\mathbf{C H}_{\mathbf{4}}$ \\
\hline $\mathrm{Ni} / \mathrm{MgO}$ & 62.9 & 37.4 & 65.9 & 4.6 & 29.5 & - \\
$\mathrm{Ni} / \mathrm{meso}-\mathrm{MgO}$ & 83.1 & 49.9 & 85.2 & 2.5 & 12.3 & - \\
\hline
\end{tabular}

Reaction conditions: 0.3 g catalyst, $450{ }^{\circ} \mathrm{C}, \mathrm{N}_{2}$ flow rate $=45 \mathrm{~mL} / \mathrm{min}$, liquid flow rate $=5.2 \mathrm{~mL} / \mathrm{h}, \mathrm{S} / \mathrm{C}=20 \mathrm{~mol} / \mathrm{mol}$. 


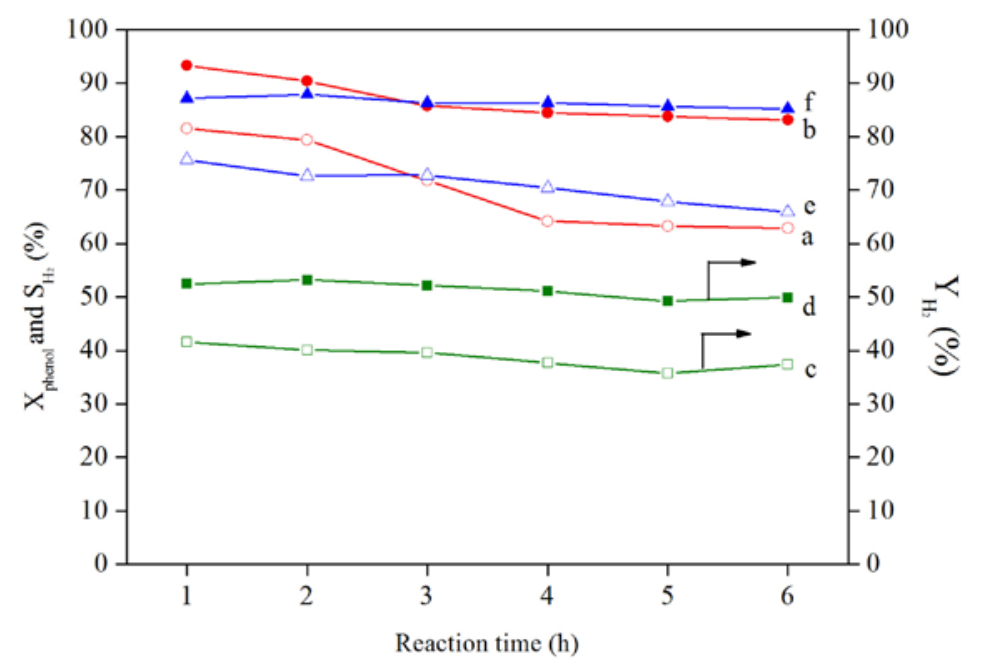

Figure 9. Phenol conversion (a,b), $\mathrm{H}_{2}$ yield (c,d), $\mathrm{H}_{2}$ selectivity (e,f) vs. reaction time over $\mathrm{Ni} / \mathrm{MgO}$ catalyst (hollow symbols) and Ni/meso-MgO catalyst (solid symbols). Reaction conditions: 0.3 g catalyst, $450{ }^{\circ} \mathrm{C}, \mathrm{N}_{2}$ flow rate $=45 \mathrm{~mL} / \mathrm{min}$, liquid flow rate $=5.2 \mathrm{~mL} / \mathrm{h}$, $\mathrm{S} / \mathrm{C}=20 \mathrm{~mol} / \mathrm{mol}$.

There were several reasons that could explain the better activity and stability of $\mathrm{Ni} / \mathrm{meso}-\mathrm{MgO}$ than $\mathrm{Ni} / \mathrm{MgO}$. First of all, the mesostructure in $\mathrm{Ni} /$ meso-MgO provided the reactants more accessible nickel active sites than the conventional $\mathrm{Ni} / \mathrm{MgO}$ catalyst. Second of all, the $\mathrm{Ni}$ particle on $\mathrm{Ni} / \mathrm{meso}-\mathrm{MgO}$ is smaller than that on $\mathrm{Ni} / \mathrm{MgO}$ (see Table 2). It is known that small Ni particles exhibited strengthened capability for suppressing the carbon deposition [12]. Third of all, the mesoporous structure of $\mathrm{Ni} /$ meso-MgO played a very important role in inhibiting the growth of the $\mathrm{Ni}$ nanoparticles during the reaction. At the same, the larger specific surface area of mesoporous $\mathrm{MgO}$ is also in favor of the dispersion of $\mathrm{Ni}$ particles on the catalyst. As a result, the catalytic activity and stability of the $\mathrm{Ni} /$ meso-MgO catalyst were improved due to the small size of the Ni particles. Last but not least, the confinement effect of the mesoporous structure can stabilize the Ni particles during the procedure of reduction and reaction.

We also calculated the turnover frequency (TOF) of phenol conversion at the initial reaction on the basis of the amount of exposed Ni listed in Table 2. At $450{ }^{\circ} \mathrm{C}$, the TOF of phenol conversion is $6.43 \mathrm{~s}^{-1}$ over $\mathrm{Ni} / \mathrm{MgO}$ vs. $6.48 \mathrm{~s}^{-1}$ over Ni/meso-MgO. The TOF values show that the specific activity of metallic Ni is almost the same for these two catalysts. The obvious difference of the phenol conversion seen in Figure 9 is mainly attributed to the Ni surface area and amount of exposed Ni for theses two catalysts.

\subsubsection{Catalytic Stability of Ni/meso-MgO Catalyst}

Figure 10 shows the stability of the Ni/meso-MgO catalyst in terms of the phenol conversion, $\mathrm{H}_{2}$ yield and selectivity vs. the time on stream (TOS), and the reaction conditions were $0.3 \mathrm{~g}$ catalyst at $450{ }^{\circ} \mathrm{C}, \mathrm{N}_{2}$ flow rate $=45 \mathrm{~mL} / \mathrm{min}$, liquid flow rate $=5.2 \mathrm{~mL} / \mathrm{h}, \mathrm{S} / \mathrm{C}=20 \mathrm{~mol} / \mathrm{mol}$, TOS $=15 \mathrm{~h}$. The $\mathrm{Ni} /$ meso-MgO catalyst showed good catalytic stability during $15 \mathrm{~h}$ on stream. The phenol conversion, 
$\mathrm{H}_{2}$ yield and $\mathrm{H}_{2}$ selectivity were almost stable up to $15 \mathrm{~h}$. During the runtime, the conversions of phenol remained at around $82.1 \%$ and the corresponding $\mathrm{H}_{2}$ yields kept at $49.5 \%$.

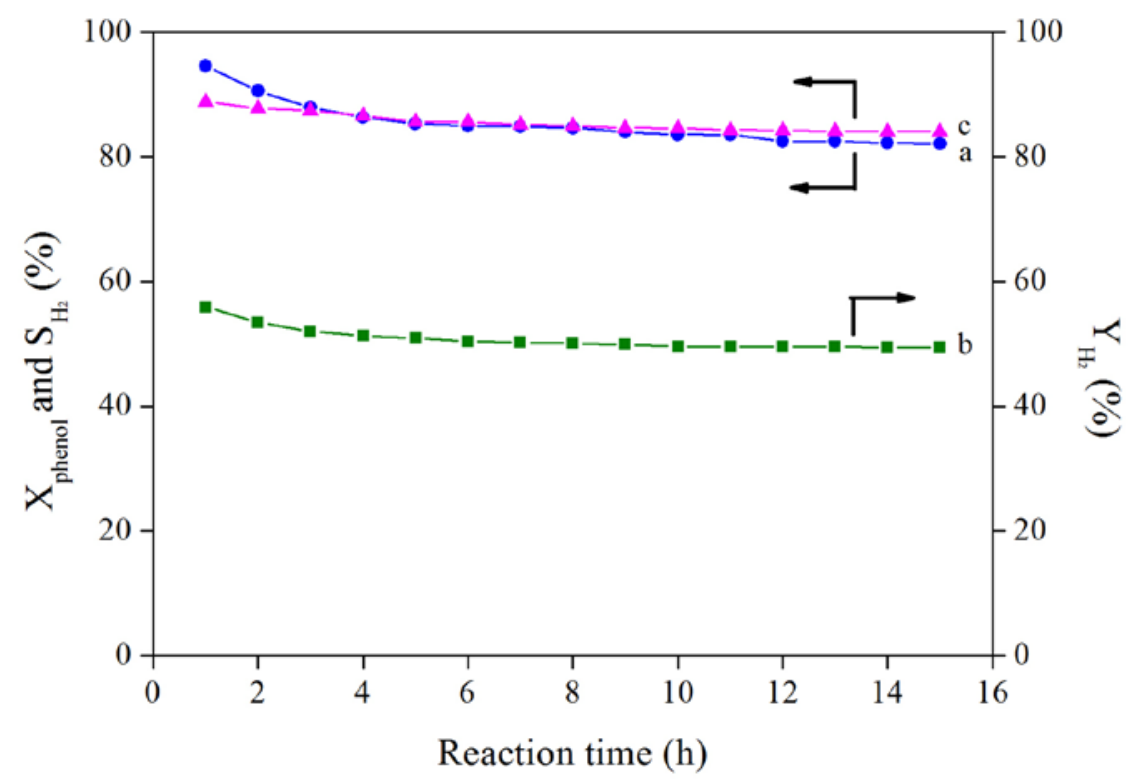

Figure 10. Phenol conversion (a), $\mathrm{H}_{2}$ yield (b) and $\mathrm{H}_{2}$ selectivity (c) vs. reaction time over $\mathrm{Ni} /$ meso-MgO catalyst. Reaction conditions: 0.3 g catalyst, $450{ }^{\circ} \mathrm{C}, \mathrm{N}_{2}$ flow rate $=45 \mathrm{~mL} / \mathrm{min}$, liquid flow rate $=5.2 \mathrm{~mL} / \mathrm{h}, \mathrm{S} / \mathrm{C}=20 \mathrm{~mol} / \mathrm{mol}$.

\subsection{Characterization of Used Catalyst}

\subsubsection{TEM Analysis of Used Catalyst}

Figure 11 shows the TEM and HRTEM images for the used Ni/MgO and Ni/meso-MgO catalysts after reaction for $6 \mathrm{~h}$. The size distribution of nickel particles is also exhibited in Figure 11. It is found from Figure 11c that the morphology of the used Ni/meso-MgO catalyst is similar to that of the fresh $\mathrm{Ni} /$ meso-MgO catalyst (see Figure 7c). In addition, the used $\mathrm{Ni} /$ meso-MgO catalyst still maintained mesoporous channels. As shown in Figure 11d, the average Ni particle size of the used Ni/meso-MgO is $5.5 \pm 0.2 \mathrm{~nm}$ based on 100 particle measurements, while the nickel particle size of the used Ni/MgO ranged from 6 to $11 \mathrm{~nm}$ and the average size is $8.56 \mathrm{~nm}$. These results indicate that the nickel particle size remained unchanged for both of the catalysts during the reaction (see Figures $7 \mathrm{~b}, \mathrm{~d}$ and $11 \mathrm{~b}, \mathrm{~d}$ ). The strong interaction between $\mathrm{Ni}$ particles and solid solution of $\mathrm{NiO}$ and $\mathrm{MgO}$ inhibited the growth of $\mathrm{Ni}$ particles [28].

The TEM and HRTEM images for the used Ni/meso-MgO catalyst after reaction for $1 \mathrm{~h}$ and $15 \mathrm{~h}$ are shown in Figure 12. It is found that the Ni particle size of the used Ni/meso-MgO catalyst is in the range of $5.6 \pm 0.2 \mathrm{~nm}$ and the $\mathrm{Ni}$ particle size remained almost unchanged until TOS $=15 \mathrm{~h}$. Simultaneously, TEM was also used to analyze the carbon deposition behaviors. From Figure 12a,c, no obvious deposits or formation of carbon whiskers were observed on the used catalyst surface. 

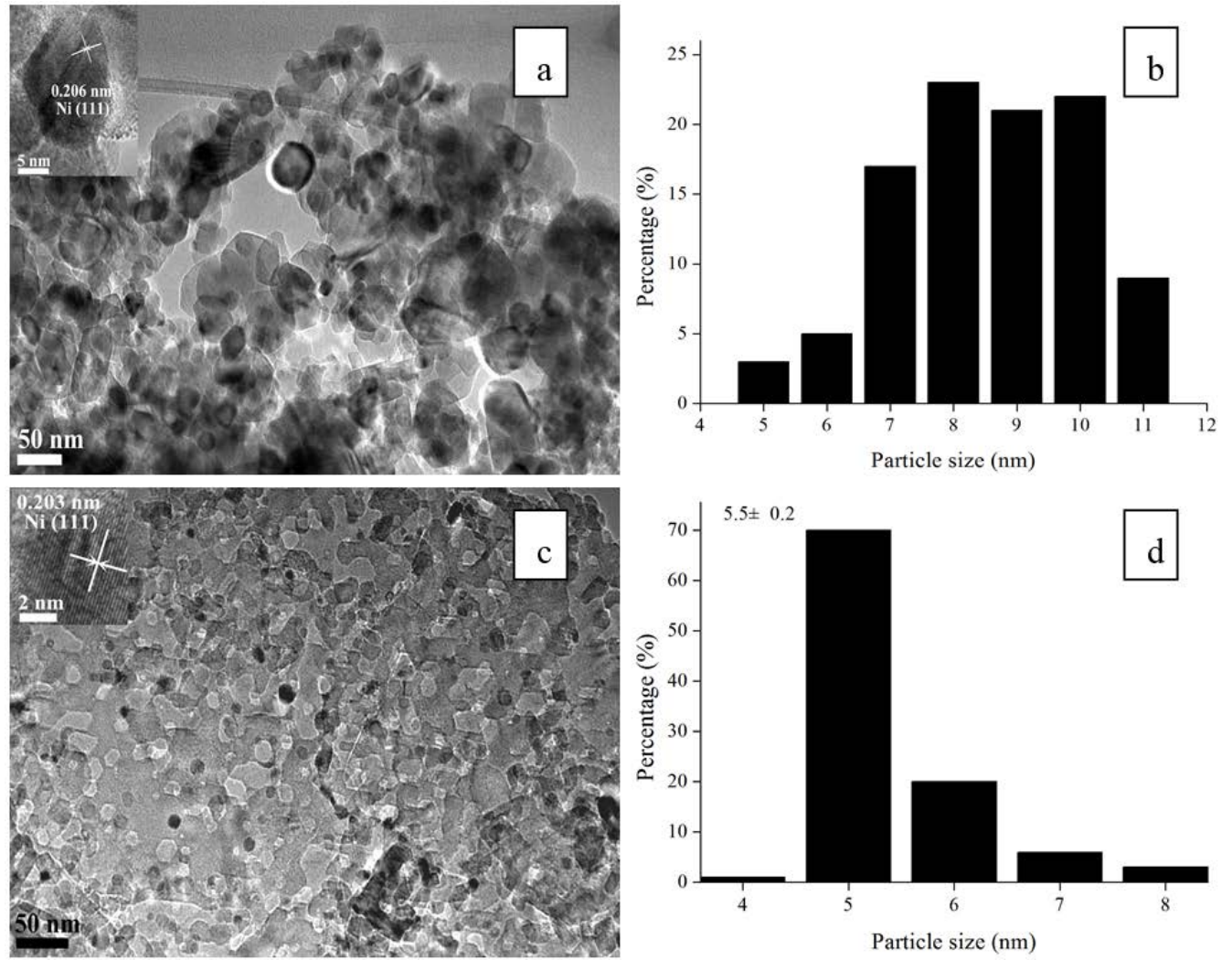

Figure 11. TEM images and Ni size distribution patterns for $(\mathbf{a}, \mathbf{b})$ used $\mathrm{Ni} / \mathrm{MgO}$ catalyst and (c,d) used Ni/meso-MgO catalyst. The used catalysts were sampled after reaction for $6 \mathrm{~h}$.
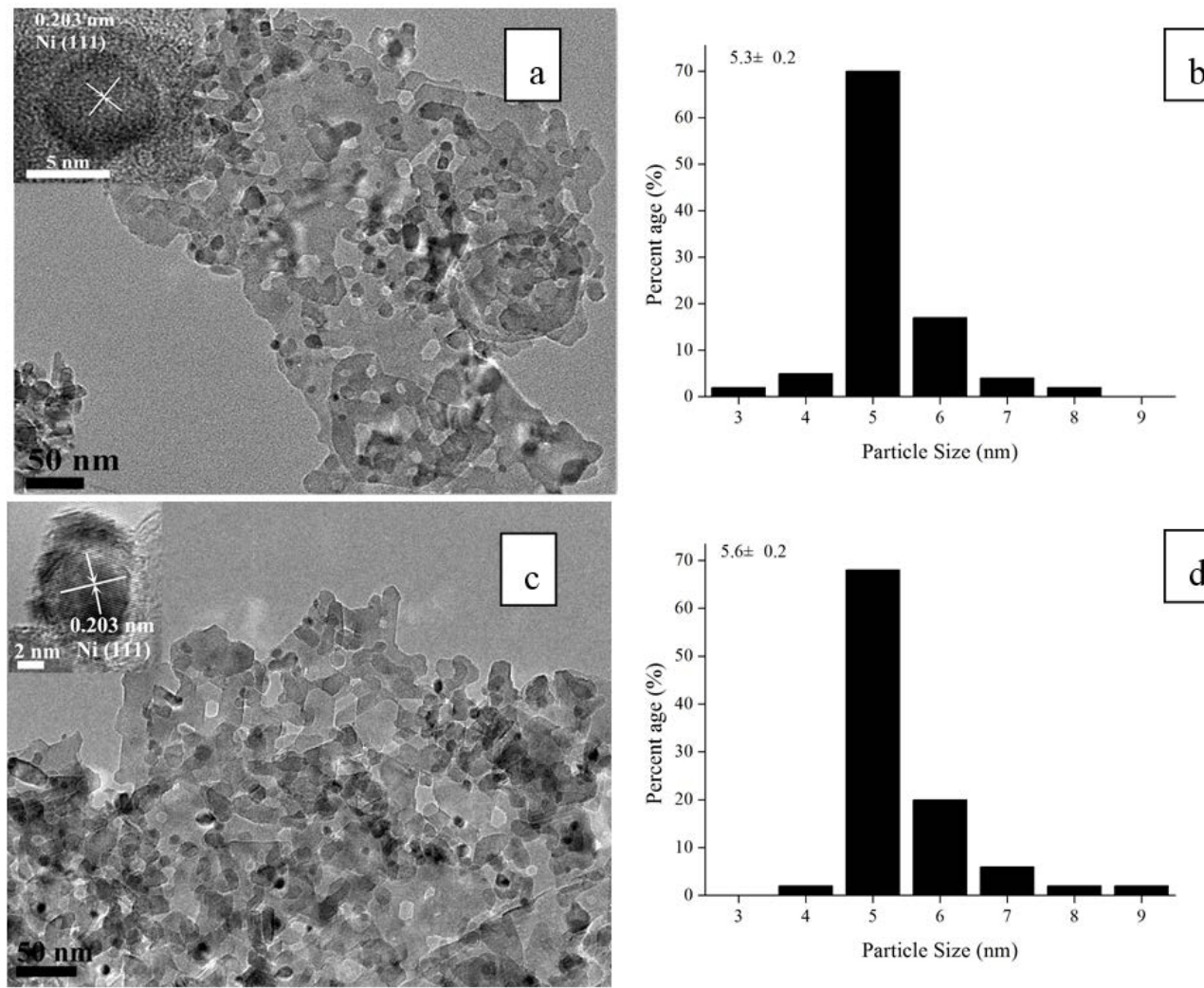

Figure 12. TEM images and Ni size distribution pictures for used $\mathrm{Ni} / \mathrm{meso}-\mathrm{MgO}$ catalysts. The used catalysts were sampled after reaction for (a,b) $1 \mathrm{~h}$ and (c,d) $15 \mathrm{~h}$. 


\subsubsection{Thermogravimetric Analysis of Used Catalyst}

Thermogravimetric analysis (TGA) was used to characterize the weight loss caused by the removal of carbon deposits. The carbon deposition over the $\mathrm{Ni} / \mathrm{MgO}$ and $\mathrm{Ni} / \mathrm{meso}-\mathrm{MgO}$ catalysts after reaction $6 \mathrm{~h}$ at $450{ }^{\circ} \mathrm{C}$ were investigated by TGA and the results are shown in Figure 13. As shown by the TGA curves in Figure 13, the total weight losses are about $8.0 \%$ and $4.8 \%$ for the used $\mathrm{Ni} / \mathrm{MgO}$ and $\mathrm{Ni} /$ meso-MgO catalysts. This indicates that the amount of carbon deposited on $\mathrm{Ni} / \mathrm{meso}-\mathrm{MgO}$ is obviously less than that on $\mathrm{Ni} / \mathrm{MgO}$. This is because the carbon deposition on $\mathrm{Ni} / \mathrm{meso}-\mathrm{MgO}$ was suppressed due to its smaller $\mathrm{Ni}$ particle size compared to that of $\mathrm{Ni} / \mathrm{MgO}$.

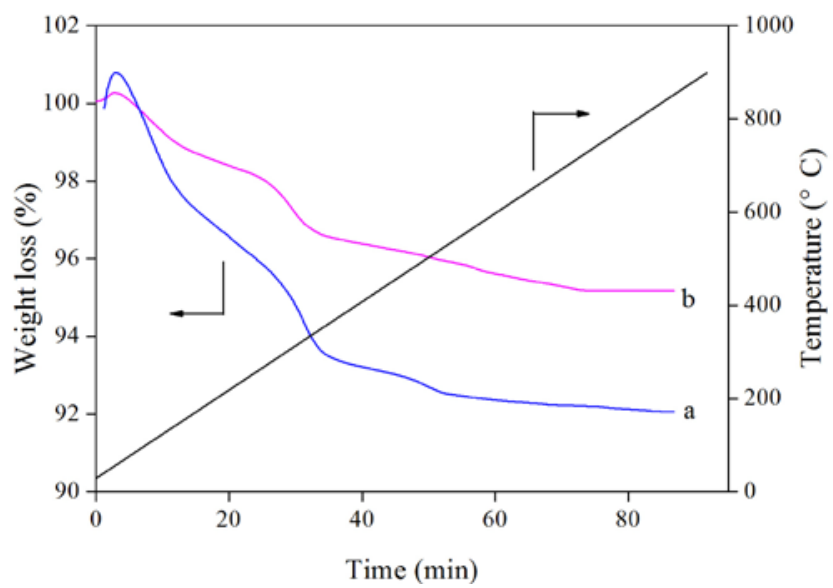

Figure 13. Thermogravimetric patterns for (a) used $\mathrm{Ni} / \mathrm{MgO}$ catalyst and (b) used $\mathrm{Ni} /$ meso-MgO catalyst. The used catalysts were sampled after reaction for $6 \mathrm{~h}$.

\section{Experimental Methods}

\subsection{Preparation of Mesoporous $\mathrm{MgO}$ and $\mathrm{Ni} / \mathrm{meso}-\mathrm{MgO}$ Catalysts}

Mesoporous $\mathrm{MgO}$ was prepared according to the literature [29]. Typically, $2.56 \mathrm{~g}$ of $\mathrm{Mg}\left(\mathrm{NO}_{3}\right)_{2} \cdot 6 \mathrm{H}_{2} \mathrm{O}$ was dissolved in $50 \mathrm{~mL}$ of distilled water and ethanol mixture (volume ratio of 1:1) to make solution A. $0.80 \mathrm{~g}$ of $\mathrm{NaOH}$ was dissolved in $50 \mathrm{~mL}$ of distilled water and ethanol mixture (volume ratio of 3:2) to make solution B. Solution A was then added dropwise into solution B and stirred vigorously for $24 \mathrm{~h}$ to form a white suspension. The suspension was transferred into a $150 \mathrm{~mL}$ Teflon-lined stainless steel autoclave and the autoclave was then maintained at $160{ }^{\circ} \mathrm{C}$ for $24 \mathrm{~h}$. After cooling to room temperature, the white product was washed with distilled water for several times, and then dried at $80{ }^{\circ} \mathrm{C}$ for $24 \mathrm{~h}$ in air. Finally, the white powder was calcined at $650{ }^{\circ} \mathrm{C}$ for $5 \mathrm{~h}$ in air and mesoporous $\mathrm{MgO}$ was obtained, designated as meso-MgO.

The Ni/meso-MgO catalyst was prepared by impregnation. Typically, a certain amount of $\mathrm{Ni}_{(}\left(\mathrm{NO}_{3}\right)_{2} \cdot 6 \mathrm{H}_{2} \mathrm{O}$ was dissolved in ethanol to make a 10.98 wt. \% Ni solution, then meso-MgO was added into the solution. After stirring for $24 \mathrm{~h}$, the mixture was transferred to an oven at $110{ }^{\circ} \mathrm{C}$ and dried. The dried composite was calcined at $650{ }^{\circ} \mathrm{C}$ for $5 \mathrm{~h}$ in air. The obtained product was NiO/meso-MgO solid solution. Before reaction, the solid solution was reduced in hydrogen flow to obtain $\mathrm{Ni} / \mathrm{meso}-\mathrm{MgO}$ catalyst.

For comparison, a 10.98 wt. \% Ni/MgO catalyst was also prepared by impregnating NiO onto MgO with the same procedure. 


\subsection{Characterization}

X-ray diffraction (XRD) patterns were tested on Germany Brueckner D8 Advance instrument (Brueckner, Siegsdorf, Germany). The Brunauer-Emmett-Teller (BET) specific surface area and $\mathrm{N}_{2}$ adsorption-desorption isotherms were obtained at $-196{ }^{\circ} \mathrm{C}$ using a Quantachrome NOVA analyzer (Quantachrome Instruments, Boynton Beach, FL, USA). Transmission electron microscopy (TEM) images were obtained on a FEI Tecnai G20 instrument (FEI Company, Hillsboro, OR, USA). Hydrogen temperature programmed reduction (TPR) measurements were performed on a PCA-1200 apparatus (Biaode, Beijing, China) equipped with a thermal conductivity detector (TCD). For each measurement, about $50 \mathrm{mg}$ of catalyst precursor was heated to $120{ }^{\circ} \mathrm{C}$ in argon flow for $30 \mathrm{~min}$ and then the sample was cooled to ambient temperature. The furnace temperature was programmed to reach $650{ }^{\circ} \mathrm{C}$ at $15.5^{\circ} \mathrm{C} / \mathrm{min}$ and kept at $650{ }^{\circ} \mathrm{C}$ for $1 \mathrm{~h}$ in a $10 \% \mathrm{H}_{2} / \mathrm{Ar}$ flow, then slowed down to the room temperature in the reducing gas. The carbon deposited on used catalysts was analyzed by thermogravimetric analysis (TGA) on TGA Q5000, TA Instruments (TA Company, New Castle, DE, USA). The dispersion of $\mathrm{Ni}(\%)$ and the average particle size of the reduced $\mathrm{Ni}$ were calculated according to the literature [30], and the calculation was as follows:

$$
\text { The number of Ni particles: } N_{1}=\frac{m_{\mathrm{Ni}}}{\frac{2}{3} \pi\left(\frac{d_{\mathrm{Ni}}}{2}\right)^{3} \rho_{\mathrm{Ni}}}
$$

The overall surface area of Ni particles: $S=2 \pi\left(\frac{d_{\mathrm{Ni}}}{2}\right)^{2} N_{1}$

$$
\text { Ni dispersion (D): } D=\frac{N_{\mathrm{S}}}{N_{\mathrm{T}}}=\frac{S k}{n_{\mathrm{Ni}} N_{\mathrm{A}}}
$$

The $\mathrm{Ni}$ particle size was calculated using Scherrer Formula from the XRD results. $\rho_{\mathrm{Ni}}=8.902 \times 10^{6} \mathrm{~g} / \mathrm{m}^{3} ; N_{\mathrm{S}}=$ total number of surface Ni atoms; $N_{\mathrm{T}}=$ total number of $\mathrm{Ni}$ atoms; $N_{\mathrm{A}}=6.02 \times 10^{23} \mathrm{~mol}^{-1}$; The $\mathrm{Ni}$ atom density $(k)$ is $1.529 \times 10^{19} \mathrm{~m}^{-2} ; M_{\mathrm{Ni}}=58.69$.

\subsection{Catalytic Activity Test}

The steam reforming of phenol was conducted in a fixed-bed reactor. Typically, $0.30 \mathrm{~g}$ catalyst precursor was placed at the center of the quartz tubular reactor (i.d. $6.0 \mathrm{~mm}$ ) and then reduced in situ in a $10 \% \mathrm{H}_{2} / \mathrm{Ar}$ flow at $650{ }^{\circ} \mathrm{C}$ for $1 \mathrm{~h}$. After reduction, the reactor was purged with $\mathrm{N}_{2}$ until $\mathrm{H}_{2}$ cannot be detected on the on-line GC. The pre-blended solution of $\mathrm{H}_{2} \mathrm{O}$ and phenol with a molar ratio of $\mathrm{S} / \mathrm{C}=20 / 1$ was pumped into an evaporator pre-heated at $220^{\circ} \mathrm{C}$. The liquid reactant was pumped at a rate of $5.2 \mathrm{~mL} / \mathrm{h}$. After vaporization, the reactants were carried to the reactor using $\mathrm{N}_{2}$ with a flow rate of $45 \mathrm{~mL} / \mathrm{min}$. After reaction, the gas products were analyzed using an on-line GC equipped with a TDX-01 column and TCD detector. The liquid products were collected by a trap at $0{ }^{\circ} \mathrm{C}$ and then analyzed using a GC equipped with a Propark Q column and FID detector. Phenol conversion, hydrogen yield and selectivity were calculated as follows:

$$
X_{\text {phenol }}=\frac{1-n_{\text {out }}}{n_{\text {in }}} \times 100 \%
$$




$$
\begin{gathered}
Y_{\mathrm{H}_{2}}=\frac{n_{\text {out }}}{n_{\mathrm{H}_{2}, \text { theory }}} \times 100 \% \\
S_{\mathrm{H}_{2}}=\frac{n_{\mathrm{H}_{2}}}{n_{\mathrm{H}_{2}}+n_{\mathrm{CO}}+n_{\mathrm{CO}_{2}}+n_{\mathrm{CH} 4}} \times 100 \%
\end{gathered}
$$

\section{Conclusions}

Mesoporous $\mathrm{Ni} /$ meso-MgO catalyst was prepared through a simple impregnation of $\mathrm{NiO}$ onto mesoporous MgO. It is found that $\mathrm{Ni}$ particles were more evenly distributed on the Ni/meso-MgO catalyst compared to the conventional $\mathrm{Ni} / \mathrm{MgO}$ catalyst. $\mathrm{Ni} /$ meso-MgO exhibited higher catalytic activity and longer-term catalytic stability in steam reforming of phenol than Ni/MgO. The mesoporous structure of $\mathrm{Ni} /$ meso-MgO limited the growth of the active metal by the "confinement effect" and stabilized $\mathrm{Ni}$ particles during the procedure of $\mathrm{NiO}$ reduction. In addition, Ni/meso-MgO exhibited stronger ability for suppressing the carbon deposition and $\mathrm{Ni}$ sintering during the steam reforming reaction. $\mathrm{Ni} / \mathrm{meso}-\mathrm{MgO}$ is believed to be a promising catalyst candidate for the steam reforming of organic compounds.

\section{Acknowledgments}

This work was supported by the Overseas Scholars Program of the Department of Education, Heilongjiang Province (No. 1155h019) as well as Program for Scientific and Technological Innovation Team Construction in University of Heilongjiang Province (No. 2011TD010).

\section{Author Contributions}

The experimental work was conceived and designed by Yuhe Wang and Xiaoxuan Yang, Xiaoxuan Yang and Yajing Wang performed the experiments; Yuhe Wang and Xiaoxuan Yang analyzed the data; Yajing Wang contributed reagents/materials/analysis tools; Xiaoxuan Yang drafted the paper. The manuscript was amended through the comments of all authors. All authors have given approval for the final version of the manuscript.

\section{Conflicts of Interest}

The authors declare no conflict of interest.

\section{References}

1. Christopher, K.; Dimitrios, R. A review on exergy comparison of hydrogen production methods from renewable energy sources. Energy Environ. Sci. 2012, 5, 6640-6651.

2. Nakamura, K.; Miyazawa, T.; Sakurai, T.; Miyao, T.; Naito, S.; Begum, N.; Kunimori, K.; Tomishige, K. Promoting effect of $\mathrm{MgO}$ addition to $\mathrm{Pt} / \mathrm{Ni} / \mathrm{CeO}_{2} / \mathrm{Al}_{2} \mathrm{O}_{3}$ in the steam gasification of biomass. Appl. Catal. B 2009, 86, 36-44. 
3. Sato, K.; Fujimoto, K. Development of new nickel based catalyst for tar reforming with superior resistance to sulfur poisoning and coking in biomass gasification. Catal. Commun. 2007, 8, 1697-1701.

4. Coll, R.; Salvado, J.; Farriol, X.; Montane, D. Steam reforming model compounds of biomass gasification tars: Conversion at different operating conditions and tendency towards coke formation. Fuel Process. Technol. 2001, 74, 19-31.

5. Li, C.S.; Suzuki, K. Tar property, analysis, reforming mechanism and model for biomass gasification-An overview. Renew. Sust. Energ. Rev. 2009, 13, 594-604.

6. Baudouin, D.; Rodemerck, U.; Krumeich, F.; Mallmann, A.; Szetom, K.C.; Ménard, H.; Veyre, L.; Candy, J.P.; Webb, P.B.; Thieuleux, C.; et al. Particle size effect in the low temperature reforming of methane by carbon dioxide on silica-supported Ni nanoparticles. J. Catal. 2013, 297, 27-34.

7. Delgado, K.H.; Maier, L.; Tischer, S.; Zellner, A.; Stotz, H.; Deutschmann, O. Surface Reaction Kinetics of Steam- and $\mathrm{CO}_{2}$-Reforming as Well as Oxidation of Methane over Nickel-Based Catalysts. Catalysts 2015, 5, 871-904.

8. Valle, B.; Remiro, A.; Aguayo, A.T.; Bilbao, J.; Gayubo, A.G. Catalysts of $\mathrm{Ni} / \alpha-\mathrm{Al}_{2} \mathrm{O}_{3}$ and $\mathrm{Ni} / \mathrm{La}_{2} \mathrm{O}_{3}-\alpha \mathrm{Al}_{2} \mathrm{O}_{3}$ for hydrogen production by steam reforming of bio-oil aqueous fraction with pyrolytic lignin retention. Int. J. Hydrogen Energy 2013, 38, 1307-1318.

9. Xu, L.L.; Song, H.L.; Chou, L.J. One-Pot Synthesis of Ordered Mesoporous NiO-CaO- $\mathrm{Al}_{2} \mathrm{O}_{3}$ Composite Oxides for Catalyzing $\mathrm{CO}_{2}$ Reforming of $\mathrm{CH}_{4}$. ACS Catal. 2012, 2, 1331-1342.

10. Sokolov, S.; Kondratenko, E.V.; Pohl, M.M.; Barkschat, A.; Rodemerck, U. Stable low-temperature dry reforming of methane over mesoporous $\mathrm{La}_{2} \mathrm{O}_{3}-\mathrm{ZrO}_{2}$ supported Ni catalyst. Appl. Catal. B 2012, 113-114, 19-30.

11. Liu, S.G.; Guan, L.X.; Li, J.P.; Zhao, N.; Wei, W.; Sun, Y.H. $\mathrm{CO}_{2}$ reforming of $\mathrm{CH}_{4}$ over stabilized mesoporous Ni-CaO-ZrO2 composites. Fuel 2008, 87, 2477-2481.

12. Bengaard, H.S.; Nørskov, J.K.; Sehested, J.; Clausen, B.S.; Nielsen, L.P.; Molenbroek, A.M.; Nielsen, J.R.R. Steam Reforming and Graphite Formation on Ni Catalysts. J. Catal. 2002, 209, 365-384.

13. Garcia, L.; French, R.; Czernik, S.; Chornet, E. Catalytic steam reforming of bio-oils for the production of hydrogen: Effects of catalyst composition. Appl. Catal. A 2000, 201, 225-239.

14. Ruckenstein, E.; Hu, Y.H. Methane partial oxidation over NiO/MgO solid solution catalysts. Appl. Catal. A 1999, 183, 85-92.

15. Wang, Y.H.; Liu, H.M.; Xu, B.Q. Durable Ni/MgO catalysts for $\mathrm{CO}_{2}$ reforming of methane: Activity and metal-support interaction. J. Mol. Catal. A 2009, 299, 44-52.

16. Sun, N.N.; Wen, X.; Wang, F.; Wei, W.; Sun, Y.H. Effect of pore structure on Ni catalyst for $\mathrm{CO}_{2}$ reforming of $\mathrm{CH}_{4}$. Energy Environ. Sci. 2010, 3, 366-369.

17. Liu, D.P.; Quek, X.Y.; Cheo, W.N.E.; Lau, R.; Borgna, A.; Yang, Y.H. MCM-41 supported nickel-based bimetallic catalysts with superior stability during carbon dioxide reforming of methane: Effect of strong metal-support interaction. J. Catal. 2009, 266, 380-390.

18. Nurunnabi, M.; Li, B.T.; Kunimori, K.; Suzuki, K.; Fujimoto, K.; Tomishige, K. Performance of NiO-MgO solid solution-supported Pt catalysts in oxidative steam reforming of methane. Appl. Catal. A 2005, 292, 272-280. 
19. Zhong, L.S.; Hu, J.S.; Wan, L.J.; Song, W.G. Facile synthesis of nanoporous anatase spheres and their environmental applications. Chem. Commun. 2008, doi:10.1039/B718300C.

20. Yu, C.C.; Zhang, L.X.; Shi, J.L.; Zhao, J.J.; Gao, J.H.; Yan, D.S. A Simple Template-Free Strategy to Synthesize Nanoporous Manganese and Nickel Oxides with Narrow Pore Size Distribution, and Their Electrochemical Properties. Adv. Funct. Mater. 2008, 18, 1544-1554.

21. Liu, D.P.; Quek, X.Y.; Wah, H.H.A.; Zeng, G.M.; Li, Y.D.; Yang, Y.H. Carbon dioxide reforming of methane over nickel-grafted SBA-15 and MCM-41 catalysts. Catal. Today 2009, 148, 243-250.

22. Morris, S.M.; Fulvio, P.F.; Jaroniec, M. Ordered Mesoporous Alumina-Supported Metal Oxides. J. Am. Chem. Soc. 2008, 130, 15210-15216.

23. Cao, L.; Man, T.; Kruk, M. Synthesis of Ultra-Large-Pore SBA-15 Silica with Two-Dimensional Hexagonal Structure Using Triisopropylbenzene as Micelle Expander. Chem. Mater. 2009, 21, 1144-1153.

24. Yu, M.J.; Zhu, K.; Liu, Z.C.; Xiao, H.P.; Deng, W.; Zhou, X.G. Carbon dioxide reforming of methane over promoted $\mathrm{Ni}_{x} \mathrm{Mg}_{1-x} \mathrm{O}$ (111) platelet catalyst derived from solvothermal synthesis. Appl. Catal. B 2014, 148-149, 177-190.

25. Park, J.Y.; Lee, Y.J.; Karandikar, P.R.; Jun, K.W.; Ha, K.S.; Park, H.G. Fischer-Tropsch catalysts deposited with size-controlled $\mathrm{Co}_{3} \mathrm{O}_{4}$ nanocrystals: Effect of Co particle size on catalytic activity and stability. Appl. Catal. A 2012, 411-412, 15-23.

26. Xu, L.L.; Miao, Z.C.; Song, H.L.; Chen, W.; Chou, L.J. Significant roles of mesostructure and basic modifier for ordered mesoporous $\mathrm{Ni} / \mathrm{CaO}-\mathrm{Al}_{2} \mathrm{O}_{3}$ catalyst towards $\mathrm{CO}_{2}$ reforming of $\mathrm{CH}_{4}$. Catal. Sci. Technol. 2014, 4, 1759-1770.

27. Park, J.Y.; Lee, Y.J.; Khanna, P.K.; Jun, K.W.; Bae, J.W.; Kim, Y.H. Alumina-supported iron oxide nanoparticles as Fischer-Tropsch catalysts: Effect of particle size of iron oxide. J. Mol. Catal. A 2010, 323, 84-90.

28. Hu, Y.H. Solid-solution catalysts for $\mathrm{CO}_{2}$ reforming of methane. Catal. Today 2009, 148, 206-211.

29. Ling, Z.X.; Zheng, M.B.; Du, Q.L.; Wang, Y.W.; Song, J.K.; Dai, W.J.; Zhang, L.F.; Ji, G.B.; Cao, J.M. Synthesis of mesoporous MgO nanoplate by an easy solvothermal-annealing method. Solid State Sci. 2011, 13, 2073-2079.

30. Bi, Q.Y.; Du, X.L.; Liu, Y.M.; Cao, Y.; He, H.Y.; Fan, K.N. Efficient Subnanometric Gold-Catalyzed Hydrogen Generation via Formic Acid Decomposition under Ambient Conditions. J. Am. Chem. Soc. 2012, 134, 8926-8933.

(C) 2015 by the authors; licensee MDPI, Basel, Switzerland. This article is an open access article distributed under the terms and conditions of the Creative Commons Attribution license (http://creativecommons.org/licenses/by/4.0/). 